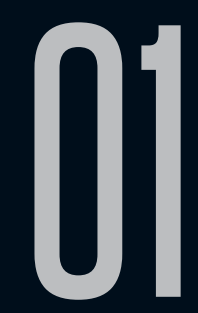

\title{
ENTREVISTA COM A ESCRITORA GIULIA MOON
}

Alexander Meireles da Silva (UFG-Catalão)

Recebido em 05 mai 2019. Aprovado em 10 jun 2019.
Alexander Meireles da Silva é Doutor em Literatura Comparada pela Universidade Federal do Rio de Janeiro (2008), Mestre em Literaturas de Língua Inglesa pela Universidade do Estado do Rio de Janeiro (2003), Especialista em Educação a Distância pelo SENAI-RJ (2003), Especialista em Literaturas de Língua Inglesa (2000), Bacharel e Licenciado em Língua Inglesa e Literaturas Correspondentes (1998) pela Universidade do Estado do Rio de Janeiro. Desde 2009 atua como Professor Associado de Língua Inglesa e Literaturas de Língua Inglesa da Unidade Acadêmica Especial de Letras e Linguística da Universidade Federal de Goiás - Regional Catalão, onde também é Professor permanente do Programa de Pós-Graduação em Estudos da Linguagem da RC/UFG. É membro fundador dos Grupos de Pesquisa Estudos do Gótico (CNPq) e Nós do Insólito: Vertentes da Ficção, da Teoria e da Crítica (CNPq) que reúnem pesquisadores e pesquisadoras de diversas universidades do Brasil. Suas pesquisas se concentram na área Literatura Fantástica. É criador de conteúdo do blog Fantasticursos (www.fantasticursos. com) e do canal do YouTube Fantasticursos (www. youtube.com/fantasticursos), onde oferece conteúdo, cursos e consultoria sobre o Fantástico na Literatura e no Cinema nas vertentes da Fantasia, Gótico, Horror e Ficção Científica. 


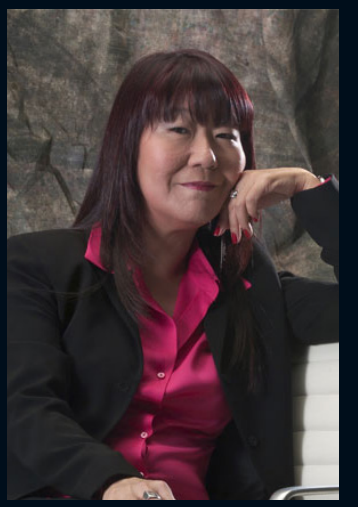

Refletindo o impacto da internet sobre o surgimento e disseminação de escritores e escritoras da Literatura Fantástica brasileira no século XXI, a ilustradora e publicitária Giulia Moon estreou como escritora nos grupos virtuais usando o pseudônimo criado pela própria autora. Condizente com suas temáticas vampirescas, Giulia é admiradora do fascínio e mistério exercido pela lua (para ela, os dois "o"s da palavra "moon" dão a impressão de dois olhos abertos em espanto). A partir do feedback recebido do público leitor sobre as histórias de vampiros que ela publicava nos fóruns de literatura, Giulia Moon primeiro estabeleceu sua base de leitores e leitoras e logo seus escritos começaram a aparecer em coletâneas e livros. Ela é autora da série Kaori, protagonizada pela vampira japonesa Kaori e que já conta com três volumes publicados: Kaori: Perfume de Vampira (Giz Editorial, 2009), Kaori 2: Coração de Vampira (Giz Editorial, 2011) e Kaori e o Samurai Sem Braço (2012). Giulia Moon já participou de diversas coletâneas de contos, sendo as mais recentes As Vampiras: Flores Mortais (Giz Editorial, 2014), com treze contos da autora cobrindo sua produção do ano 2000 até 2014 e Histórias Felinas (SESI-SP, 2016) em parceria com Helena Gomes. Como a principal voz feminina da Literatura de Vampiros no Brasil, Moon possui fãs que comparecem em eventos literários vestidos como seus personagens e a chamam de "titia Giu". Além de ministrar oficinas literárias e participar de projetos como o intitulado Fantásticas, a escritora pode ser encontrada nas redes sociais conversando sobre vampiros, animes, gatos e rock japonês. O site oficial dela é www.giuliamoon.com.br

Na entrevista abaixo, Giulia Moon fala sobre os desafios de se trabalhar com a tradição do vampiro, os desafios de se trabalhar com o personagem no contexto do século vinte e um e outros temas. 
P.: Olá Giulia! Primeiramente agradeço imensamente em nome da Revista ABUSÕES pela sua disponibilidade para esta edição sobre os 200 anos do conto "O Vampiro" (1819), de John Polidori. Sua presença aqui reitera a meta dos editores em produzir um número de referência sobre os seres da noite. Neste sentido, fale um pouco sobre a escritora Giulia Moon. Onde, quando e como surgiu uma das mais representativas vozes femininas hoje da literatura brasileira no campo dos vampiros?

R.: Muito obrigada pela oportunidade de falar um pouco sobre um tema que adoro: os vampiros. E ainda mais para uma edição histórica. Espero que a nossa conversa, aqui, esteja à altura! Acho que a Giulia escritora esteve comigo desde que nasci, mas só teve liberdade para se mostrar bem mais tarde. Desde pequena, sempre fui uma apaixonada por histórias, quando tinha uns cinco ou seis anos, costumava adormecer imaginando enredos alternativos para os personagens dos livros infantis que minha avó lia em japonês para mim. Depois que aprendi um pouco de japonês, passei a devorar mangás. E como tinha habilidade para o desenho, logo passei a produzir meus próprios mangás. Na época da adolescência, passava quase todo o tempo livre desenhando mangás enormes, com enredos complicadíssimos, que muitas vezes nem chegavam a terminar... Pouca gente sabia dessas minhas "obras-primas", só a família e alguns amigos da escola. Ninguém levava muito a sério esse meu talento, nem eu! Então fui aprender uma profissão. Fiz a faculdade de Publicidade e Propaganda pela FAAP, em São Paulo, e trabalhei como diretora de arte em agências durante vários anos. Até que, em 2000, navegando à toa pela internet, coloquei uma palavra mágica no 
buscador: "vampiros". Eu tinha acabado de devorar vários livros de Anne Rice e estava fascinada pelo tema. Acabei entrando num Yahoo! Groups (lembram-se deles?) chamado Tinta Rubra, de escritores amadores que escreviam contos de vampiros. Foi como se uma porta encantada se abrisse: eu finalmente tinha a oportunidade de contar histórias para um público maior! Passei vários anos no grupo, que chegou a ter cerca de 600 participantes, publicando pelo menos uma vez por semana uma história de vampiros. Pela recepção que obtive, percebi que as minhas histórias poderiam conquistar um público mais amplo. $\mathrm{E}$ foi graças ao incentivo desses amigos do grupo, que lancei o meu primeiro livro em 2003. Chamava-se Luar de Vampiros, e trazia dez contos de vampiros numa edição paga de 500 exemplares. Foi um marco na minha vida. Pela primeira vez eu me sentia uma "escritora". E, pela primeira vez, percebi que queria levar a sério essa profissão. No ano seguinte, a Landy Editora se interessou em publicar meus contos. Por lá saíram mais duas coletâneas: Vampiros no Espelho (2004) e A Dama-Morcega (2006). Senti que estava na hora de me dedicar a um projeto mais ambicioso e, em 2009, lancei o meu primeiro romance: Kaori: Perfume de Vampira, pela Giz Editorial, que teve a coragem de bancar um livro que fugia completamente dos padrões da época. Era uma história de vampiros com uma exótica heroína japonesa, que, longe de ser uma aristocrata, era uma garota de programa que tinha certo gosto por perambular em locais sórdidos. A história era contada em capítulos alternados entre o passado no Japão feudal e o presente numa São Paulo agitada e contemporânea. E, para completar, a autora fazia questão de usar como capa 
apenas um grande ideograma japonês. E o interessante disso tudo é que essa química deu certo. Hoje, dez anos depois, o livro ainda é lido e comentado e Kaori já estreou mais dois títulos: Kaori 2: Coração de Vampira e Kaori e o Samurai Sem Braço.

P.: Considerando a proposta desta edição da ABUSÕES, como você lida com a tradição da literatura de vampiros? É uma referência para se seguir, subverter ou inovar?

R.: A tradição, na minha opinião, é para se conhecer. É importante saber que os vampiros fazem parte do nosso imaginário há muito tempo, ter o conhecimento de que eles, quase como espécimes reais, evoluíram de uma forma primitiva para uma criatura complexa. E que esses seres de dentes afiados desde sempre fascinaram a Humanidade e já eram populares mesmo antes do Drácula se tornar a sua representação mais conhecida. Uma obra muito interessante a abordar esse aspecto é o livro "O vampiro antes de Drácula", de Humberto Moura Filho e Martha Argel. É uma coletânea de contos AD (Antes de Drácula), mas os textos que acompanham cada conto são muito bons e elucidativos. Muitas vezes, as inovações ou as subversões, se realizadas por quem não conhece o tema a fundo, nada mais são do que uma volta a algum ponto da evolução vampiresca, ou se afastam tanto das características do vampiro que acabam se tornando representação de algum outro ser fantástico. Então é preciso, antes de tudo, conhecer. Claro que isso não quer dizer que seja proibido mudar o que é conhecido. Acredito, acima de tudo, na liberdade de criação. Então, que se subverta, que se inove e se recrie... Mas sem perder a essência do vampiro como uma criatura que preda 
pelo sangue, e possui uma similaridade sombria com os seres humanos. Isso é respeitar a sua história e a sua caminhada até os dias de hoje.

P.: A seu ver, qual é a importância do conto de Polidori para o desenvolvimento da imagem dos vampiros como conhecemos hoje?

R.: Adoro toda a mística que existe por trás da criação desse conto - talvez muito mais do que o conto em si. Acho fascinante a ideia de que Frankestein de Mary Shelley e $O$ Vampiro de Polidori nasceram, como embriões, numa mesma noite tempestuosa na Villa Diodati. Quanto ao conto, não há como negar a sua importância histórica, o seu pioneirismo em popularizar pela primeira vez o vampiro como um personagem sutil, bemnascido e envolvente. Com Lorde Ruthven, o vampiro deixou para trás, definitivamente, a criatura suja, feia e malvada vestida com mortalha ou farrapos dos séculos anteriores e tornou-se um aristocrata refinado, sedutor e imoral. As sementes plantadas em $O$ Vampiro floresceriam de forma mais evoluída depois em Drácula, com o vampiro assumindo a sua forma clássica e mais conhecida.

P.: Como a criadora da sensual vampira Kaori vê a representação das vampiras na literatura do gênero?

R.: Durante muito tempo, a imagem do vampiro esteve ligada a devassidão, ao imoral, ao proibido e socialmente inaceitável. E essa carga se torna especialmente pesada se aplicada à imagem da vampira, pois as mulheres desde sempre sofreram com a constante opressão sexual imposta pela sociedade. O público 
acostumou-se a associar a vampira a uma criatura sexualmente agressiva, que se vale de sua condição feminina para levar os homens (ou mulheres) à perdição, tanto que a expressão vamp é utilizada como sinônimo de mulher fatal. Já tivemos vampiras notáveis como Clarimunda de A Morte Amorosa, de Theóphile Gautier, ou Carmilla, de Sheridan Le Fanu, nesse modelo. Mas cada vez mais as vampiras, como personagens, estão evoluindo junto com a própria literatura vampiresca, que sempre se caracterizou por refletir a sociedade do seu tempo. Mirian Blaylock de Fome de Viver, de Whitley Strieber, e Pandora, de Anne Rice, são exemplos da literatura do final do século vinte. Na época que lancei Kaori, dez anos atrás, o livro de vampiros mais popular era Crepúsculo, um romance YA de Stephenie Meyer, e a personagem feminina em voga era Bella Swan, que não era vampira, e sim uma garota humana que almeja unirse com o seu amor - um vampiro apaixonado e politicamente correto. Quando criei Kaori, eu quis mostrar ao público vampiros clássicos, definitivamente ferozes e predadores, sem essa de ser "bonzinho". Kaori é assim, mas é também uma mulher livre: solitária e ferida por acontecimentos do passado, mas que não faz drama de sua condição e vai à luta, seja qual for o obstáculo à sua frente. Kaori se interessa pelos humanos e acha graça nas convenções da sociedade dos homens. Ela vive à margem dessa sociedade, e aceita apenas as regras que Ihe convêm. Por ser uma outsider, ela não precisa se apegar a essa sociedade, como não se apegou a outras pelas quais passou e sobreviveu. Essa perspectiva da passagem de tempo é um ponto de vista bem interessante, que os vampiros - e as 
vampiras - podem nos proporcionar. Quem sabe que espécie de vampira pode surgir nos tempos que vivemos? Eu abordei o tema do protagonismo feminino na minha última coletânea, Flores Mortais, com contos só de vampiras. Embora menos conhecida do que a série Kaori, tenho muito carinho por esse livro, pois fala de mulheres de todos os tipos.

P.: Já em 1897, quando Drácula foi lançado, alguns críticos disseram que não havia lugar para vampiros em meio a uma sociedade industrial como a Inglaterra vitoriana. Dentro deste quadro, quais são os desafios para se escrever sobre estes seres em pleno século vinte e um? Quem é o vampiro hoje?

R.: Vejo os vampiros como criaturas adaptáveis a qualquer ambiente. Como seres inteligentes que são e, graças a sua semelhança com seres humanos, eles transitam em ambientes de qualquer época. Inclusive, acho que hoje, em que o virtual substitui cada vez mais o real, o mundo está especialmente amigável para os vampiros. Se antigamente você podia descobrir um vampiro ao perceber que ele nunca saía à luz do dia, ou não tinha reflexo no espelho, por exemplo, hoje as videochamadas, as compras online, os relacionamentos estabelecidos virtualmente possibilitam ao vampiro fazer qualquer coisa sem sair de sua casa. Talvez até comprar humanos no dark web para o seu jantar delivery.

P.: Como uma das precursoras da literatura de vampiros no Brasil, como você vê o meio hoje em termos de quem escreve? Houve mudanças em relação ao início dos anos 2000? E quais são as tendências? 
R.: Na época, publicar na internet era uma novidade fascinante, e ter um livro impresso em papel era um sonho quase impossível. Se não me engano, havia apenas uma editora que se propunha a publicar livros pagos pelo autor, mas não havia grande demanda, pois não havia muita gente que se propusesse a escrever esse tipo de livros. Os livros de fantasia, ficção científica e terror brasileiros eram restritos ao público infantojuvenil. Se você, adulto, quisesse ler, havia os bestsellers estrangeiros. Então vieram os filmes como Senhor dos Anéis, Harry Potter, e, no caso específico dos vampiros, Crepúsculo, mostrando que existia no país um público ávido pela literatura de entretenimento. A internet abria espaço para que qualquer um, contanto que tivesse um texto na mão, ou no HD, pudesse publicar num blog, num site, num grupo de discussão no Orkut e depois, no Facebook. Houve uma multiplicação de aspirantes a escritor produzindo livros de vampiros - e de editoras que os atendiam com publicações pagas. Publicou-se muita coisa ruim, mas também algumas coisas muito boas. Mas havia o problema da venda desses livros, da distribuição em livrarias, tinha muito autor com a casa abarrotada de livros encalhados. E hoje temos a Amazon, que queiram ou não, resolveu esse problema, possibilitando ao autor chegar ao público mais facilmente e publicar livros virtuais de baixo custo. A tendência, eu acredito, é agora refinar a qualidade do que é produzido. Os autores estão trabalhando de uma forma mais profissional, os leitores estão amadurecendo, se tornando mais exigentes.

P.: Você poderia indicar nomes e obras indispensáveis para conhecer o que é produzido na literatura brasileira em termos 
de obras, autores e autoras, blogs e outras redes que abordam o tema vampiros?

R.: Se você ainda não leu André Vianco, precisa conhecer. Ele é o autor de livros de vampiros de maior sucesso no Brasil, suas obras trazem sempre muita ação e aventura, em ritmo cinematográfico. Comece com Os Sete, o seu primeiro livro.

Um autor bem conhecido nesse meio é Adriano Siqueira. Ele é um pioneiro autodidata que conhece muito sobre vampiros e coleciona milhões de peças sobre o tema. Seus contos de vampiros são curtos e muitas vezes bem engraçados, e têm o encanto ingênuo da simplicidade.

Se você quer conhecer uma ótima personagem feminina vampiresca: Lucila. Precisa ler os dois livros da Martha Argel: Ligações Perigosas e Amores Perigosos. Ah, é dela, também, o excelente livro $O$ Vampiro da Mata Atlântica, que mistura ecologia e vampiros com muito conhecimento de causa!

Se você curte baladas, cultura, história, música e curiosidades vampirescas, não deixe de visitar os domínios do Lord A: a Rede Vamp e a Vox Vampyrica.

E, por último, se quiser conhecer os meus livros, poderá encontrálos pela internet, nos sites das livrarias como Saraiva, Amazon, etc.

P.: O que você poderia nos contar sobre seus novos projetos? O que Giulia Moon vem fazendo?

R.: Nos últimos anos, tive o grande prazer de escrever em parceria com ótimas autoras. Lancei a coletânea Histórias Felinas com Helena Gomes (2016) e o romance juvenil A Gótica que Não Gostava de Fantasmas (2017) com Regina Drummond, ambos 
pela SESI-SP Editora. Está em fase final um livro de terror, escrito a quatro mãos também com Helena Gomes, cujos detalhes ainda não posso divulgar. Fora isso, venho dando oficinas literárias no Fome de Letras, antigo Escrevivendo, desde 2015 em parceria com o escritor Walter Tierno. O nosso Projeto Fantásticas, em que o autor participa do processo completo do nascimento de um livro, escrevendo, discutindo, revisando e acompanhando os bastidores de uma editora, em 2019 já vai para o terceiro volume, e tem recebido muitos elogios pela qualidade dos contos, do design e do acabamento. E tem a saga Kaori, que continua me dando alegrias e conquistando novos leitores a cada dia, cujo terceiro volume eu pretendo escrever em breve. 